\title{
IMPLEMENTASI PEMBENTUKAN PUSAT PELAYANAN INFORMASI DAN PENGADUAN (PINDU)
}

\author{
Hasniah Hasan \\ Magister Terapan Studi Pemerintahan IPDN, Jatinangor, Sumedang 45363
}

\begin{abstract}
The Information and Complaint Service Center (PINDU) in Pinrang Regency is an innovation in the field of information and complaints services, which aims to realize good governance and integrity.This study uses a type of qualitative research with descriptive methods. The researcher used data collection techniques in the form of in-depth interviews, observations, and documentation. While the analysis data namely data reduction, data display, and conclusion drawing.Based on the results of research and discussion, the implementation of the formation of PINDU (Information and Complaint Service Center) in Pinrang Regency, in terms of the dimensions of communication, resources, disposition, and bureaucratic structure, has generally been going well but needs to be optimized. This is influenced by supporting factors, namely support (political will), resources (capacity), and the value of benefits (value). Whereas the inhibiting factor is the existence of errors and mistakes in determining access channels, the lack of involvement of non-government parties, and a decrease in the PINDU budget allocation each year. The efforts made in overcoming these obstacles are to build a conducive political environment; carry out good leadership (leadership); do comprehensive planning; build synergy with all stakeholders; run data transparency (transparency / visibility) in service; provide adequate budgets; provide supporting infrastructure technology; stimulate and motivate the birth of innovation (innovation) and new creativity.
\end{abstract}

\begin{abstract}
Abstrak: Pusat Pelayanan Informasi dan Pengaduan (PINDU) di Kabupaten Pinrang merupakan sebuah inovasi di bidang pelayanan informasi dan pengaduan, yang bertujuan untuk mewujudkan tata pemerintahan yang baik dan berintegritas. Penelitian ini menggunakan jenis penelitian kualitatif dengan metode deskriptif. Peneliti menggunakan teknik pengumpulan data berupa wawancara, observasi, dan dokumentasi. Sedangkan analisis data yaitu reduksi data, display data, dan penarikan kesimpulan (conclusion drawing). Berdasarkan hasil penelitian dan pembahasan, implementasi pembentukan PINDU (Pusat Pelayanan Informasi dan Pengaduan) di Kabupaten Pinrang, ditinjau dari dimensi komunikasi, sumber daya, disposisi, dan struktur birokrasi, secara umum sudah berjalan baik namun perlu dioptimalkan lagi. Hal tersebut dipengaruhi oleh faktor pendukung, yaitu support (political will), sumberdaya (capacity), dan nilai manfaat (value). Sedangkan faktor penghambatnya adalah adanya kesalahan-kesalahan dan kekeliruan dalam penentuan kanal akses, minimnya keterlibatan pihak non pemerintah, dan penurunan alokasi anggaran PINDU setiap tahunnya. Adapun upaya yang dilakukan dalam mengatasi berbagai hambatan tersebut adalah membangun suasana politik (political environment) yang kondusif; menjalankan kepemimpinan (leadership) yang baik; melakukan perencanaan (planning) yang komprehensif; membangun sinergitas dengan semua stakeholders; menjalankan transparansi data (transparency/visibility) dalam pelayanan; memberikan alokasi anggaran (budgets) yang memadai; menyediakan sarana prasarana teknologi (technology) pendukung; merangsang serta memotivasi lahirnya inovasi (Innovation) dan kreativitas baru.
\end{abstract}

Kata Kunci: implementasi, Pindu, pelayanan publik

\section{PENDAHULUAN}

Pemerintah mengeluarkan UndangUndang Nomor 14 Tahun 2008 tentang Keterbukaan Informasi Publik sebagai salah satu produk hukum Indonesia yang dikeluarkan dalam memberikan kewajiban kepada setiap setiap badan publik untuk membuka akses bagi setiap pemohon informasi publik untuk mendapatkan informasi publik kecuali beberapa informasi tertentu. Undang-undang ini bertujuan untuk menjamin hak warga Negara untuk mengetahui rencana pembuatan kebijakan publik dan mendorong partisipasi masyarakat dalam proses kebijakan publik, serta mewujudkan penyelenggaraan Negara yang baik, yaitu yang transparan, efektif dan efisien, akuntabel serta dapat dipertanggungjawabkan. Oleh karena itu, dalam mengimplementasikan dan menjalankan amanat Undang-Undang Dasar 1945, Undang-Undang Nomor 25 Tahun 2009 tentang Pelayanan Publik dan UndangUndang Nomor 14 Tahun 2008 tentang 
Keterbukaan Informasi Publik, serta Peraturan Menteri Pendayagunaan Aparatur Negara dan Reformasi Birokrasi Nomor 30 Tahun 2014 tentang Pedoman Inovasi Pelayanan Publik, pemerintah Kabupaten Pinrang merealisasikannya dalam bentuk kebijakan dengan menghadirkan sebuah inovasi program yang dapat menyediakan informasi dan mengelola pengaduan masyarakat. Program tersebut disebut dengan PINDU kependekan dari Pusat Pelayanan Informasi dan Pengaduan yang diatur dalam Peraturan Bupati Pinrang Nomor 25 Tahun 2014 tentang Pembentukan Pusat Pelayanan Informasi dan Pengaduan (PINDU) Kabupaten Pinrang.

Pembentukan PINDU ini merupakan upaya Pemerintah Kabupaten Pinrang memfasilitasi warga masyarakatnya menjangkau dan memperoleh informasi yang dibutuhkan, sebab ketersediaan informasi akan membantu meningkatkan kualitas sumber daya manusia pada semua tingkatan mulai dari pedesaan hingga perkotaan, sehingga melahirkan sumber daya manusia yang berwawasan baik, produktif dan kompetitif. Selain itu, melalui program PINDU ini juga dapat mendorong partisipasi masyarakat untuk meningkatkan kualitas pelayanan publik pada semua aspek pembangunan.

Dengan menerapkan sistem berbasis online yang didukung dengan perangkat teknologi modern, kepentingan masyarakat Pinrang akan disediakan dan dilayani dengan baik dengan cara yang sederhana, mudah dan efektif. E-Government merupakan bentuk implementasi pelayanan publik yang berbasis teknologi informasi dan komunikasi, sebagai media informasi dan sarana komunikasi interaktif antara Pemerintah dengan pihak-pihak lain baik kelompok masyarakat, kalangan bisnis maupun antar sesama lembaga pemerintahan.

Implementasi E-Government dalam penerapannya dimulai dari bentuk layanan yang sederhana yaitu penyediaan informasi dan data-data berbasis komputer tentang pelaksanaan penyelenggaraan pemerintahan dan pembangunan sebagai bentuk wujud keter- bukaan (transparancy) dalam pelaksanaan pelayanan publik.

Dalam mendukung pelaksanaan tugas dapat berjalan dengan baik, maka disadari bahwa lingkungan eksternal sangat berpengaruh, mengingat setiap aspek kegiatan yang dilakukan PINDU Kabupaten Pinrang untuk menjangkau wilayah-wilayah yang jauh karena ketika mendapatkan pengaduan, SKPD terkait harus menyelesaikan dengan turun langsung ke lapangan. Kondisi topografi Kabupaten Pinrang bervariasi dari kondisi wilayah pesisir, datar hingga gunung. Hal ini bisa menjadi kendala dalam penyelesaian pengaduan, karena dapat mengakibatkan keterlambatan penyelesaian pengaduan. Untuk penyelesaian pengaduan harus menyesuaikan dengan keadaan geografis Kabupaten Pinrang, dengan melihat luas wilayah $1.961,77$ serta kondisi geografis di Kabupaten Pinrang yang sangat luas ini akan menjadi persoalan tersendiri bagi SKPD Kabupaten Pinrang yang mendapat keluhan dari masyarakat pinrang karena di wilayah manapun pengaduan itu datang wajib segera diselesaikan dengan mendatangi wilayah tersebut. Bukan hanya itu, menerapkan sistem berbasis online (E-Government) harus didukung dengan jaringan telekomunikasi, server, serta penguasaan dan penggunaan internet dari masyarakat Kabupaten Pinrang.

Disamping wilayah yang luas dengan 12 kecamatan dan 108 desa/kelurahan, persebaran jumlah penduduk berdasarkan kepadatan penduduk tiap kecamatan di Kabupaten Pinrang. Jumlah penduduk Kabupaten Pinrang tiap tahun semakin bertambah, dengan demikian akan menjadi kerja keras pemerintah Kabupaten Pinrang dalam memberikan pembangunan dan pelayanan publik, terkhusus PINDU Kabupaten Pinrang yang menjadi wadah partisipasi masyarkat dalam pengawasan pembangunan dan pelayanan publik yang akan mendapatkan pelaporan pengaduan dari masyarakat sehingga menekankan untuk pemberian pelayanan yang cepat dan tepat.

Dengan demikian maka pelayanan informasi dan penyampaian pengaduan masyarakat Kabupaten Pinrang harus diimbangi dengan 
jumlah pegawai negeri sipil yang ada pada Kantor PINDU Kabupaten Pinrang. Pegawai Negeri Sipil pada Kantor PINDU Kabupaten Pinrang yang hanya sebanyak 4 orang, melihat jumlah tenaga pegawai yang sedikit maka akan membuat PINDU (Pusat Pelayanan Informasi dan Pengaduan) Kabupaten Pinrang bekerja keras ketika pelaporan pengaduan banyak dari masyarakat Kabupaten Pinrang.

Sumber pembiayaan dan penganggaran lebih rincinya dijabarkan dalam Dokumen Pelaksanaan Anggaran (DPA) pada Sekretariat Daerah Kabupaten Pinrang. Anggaran yang diberikan pada PINDU Kabupaten Pinrang tiap tahunnya mengalami penurunan. Mungkin hal disebabkan karena PINDU Kabupaten Pinrang hanya sebagai sarana bagi masyarakat Kabupaten Pinrang mendapatkan informasi dan menyampaikan pengaduan. Namun dapat menjadi hambatan karena PINDU Kabupaten Pinrang merupakan implementasi e-government berbasis teknologi informasi yang harus selalu diperbaharui mengikuti perkembangan zaman. Sebagaimana gambaran kondisi keuangan PINDU Kabupaten Pinrang, maka dukungan peralatan dan perlengkapan juga dibutuhkan untuk mendukung operasional pelayanan bagi masyarakat Kabupaten Pinrang.

Hasil dari pelaksanaan tugas dan fungsi PINDU Kabupaten Pinrang dapat dari beberapa pengaduan masyarakat. Beberapa SKPD Kabupaten Pinrang masih mendapatkan pengaduan dari masyarakat dan beberapa pengaduan masih ada yang belum terselesaikan. Untuk menyampaikan pengaduan masyarakat bisa menghubungi melalui sms, telepon, membuka aplikasi resmi atau datang langsung ke PINDU. Apabila laporan pengaduan masyarakat memenuhi kriteria, maka PINDU segera menyampaikan kepada SKPD atau unit kerja yang terkait untuk menanggapinya dalam waktu tidak lebih dari 2 (dua) hari apabila melibatkan satu SKPD dan tidak lebih dari 6 (enam) hari apabila melibatkan lebih dari 1 SKPD dan disampaikan melalui PINDU.

Dari uraian-uraian di atas dan terobosan inovatif berbasis e-government yang dilakukan Pemerintah Kabupaten Pinrang tersebutlah yang melatarbelakangi penulisan bagaimana implementasi dari program layanan pengaduan oleh pemerintah Kabupaten Pinrang dengan judul Implementasi Pembentukan PINDU di Kabupaten Pinrang Provinsi Sulawesi Selatan.

\section{METODE}

Desain penelitian yang digunakan penelitian ini adalah metode penelitian kualitatif dengan pendekatan deskriptif. Metode kualitatif digunakan untuk mendapatkan data yang mendalam, suatu data yang mengandung makna. Teknik pengumpulan data dalam penelitian ini menggunakan metode triangulasi kombinasi yakni antara triangulasi sumber data dan triangulasi metode dimana penemuan data diperoleh dari berbagai sumber seperti wawancara, observasi dan dokumentasi yang diperoleh dari berbagai informan. Semua data yang sudah terkumpul akan dianalisis oleh peneliti untuk diambil sebuah kesimpulan yang bersifat kualitatif deskriptif. Analisis data adalah proses mengatur urutan data, mengorganisasikannya ke dalam suatu pola, kategori dan satuan uraian dasar. Milles and Huberman menyatakan aktifitas dalam analisis data kualitatif dilakukan secara interaktif dan berlangsung secara terus menerus sampai tuntas sehingga datanya sudah jenuh, aktivitas dalam analisis data", antara lain: reduksi data, penyajian data dan kesimpulan.

\section{HASIL DAN PEMBAHASAN \\ Implementasi Pembentukan PINDU}

Dalam rangka implementasi kebijakan pembentukan Pusat Pelayanan lnformasi dan Pengaduan (PINDU) Kabupaten Pinrang, agar mencapai tujuan yang diharapkan, maka dapat diketahui dengan melihat 4 (empat) dimensi, sesuai pendapat Edward III dalam Widodo (2010:29), yaitu : (1) komunikasi, (2) sumberdaya, (3) disposisi dan (4) struktur birokrasi.

\section{Komunikasi}

Komunikasi dalam penelitian ini meninjau beberapa aspek, antara lain transmisi (trasmission), kejelasan (clarity) dan konsistensi (consistency). Aspek transmisi (trans- 
mission) menghendaki agar kebijakan publik disampaikan tidak hanya kepada pelaksana (implementors) kebijakan tetapi juga disampaikan kepada kelompok sasaran kebijakan dan pihak lain yang berkepentingan baik secara langsung maupun tidak langsung. Dalam program PINDU di Kabupaten Pinrang, pelaksana (implementors) kebijakan PINDU adalah Koordinator Tim Teknis PINDU sedangkan kelompok sasaran adalah seluruh stakeholders yang ada di Kabupaten Pinrang.

Dari aspek kejelasan (clarity), komunikasi yang dibangun oleh Pemerintah Kabupaten Pinrang dalam mengimplementasikan program PINDU, sangat detail dan jelas sehingga tidak menimbulkan kebingungan dan multitafsir di masyarakat. Keterbukaan informasi dan transparansi menjadi pedoman penting dari program PINDU ini. Pemerintah Kabupaten Pinrang sangat konsisten dalam mengimplementasikan pembentukan program PINDU di Kabupaten Pinrang. Komitmen Pemerintah Kabupaten Pinrang dalam pembentukan program PINDU mendapatkan dukungan yang luas dari masyarakatnya karena adanya konsistensi (consistency) Pemerintah Kabupaten Pinrang untuk menerapkan dan mengimplementasikan program PINDU ini dengan sungguh-sungguh.

\section{Sumberdaya}

Sumberdaya meliputi sumberdaya manusia, sumberdaya anggaran, dan sumberdaya peralatan dan sumberdaya kewenangan. Dari hasil penelitian, Kantor PINDU di Kabupaten Pinrang, dijalankan oleh 4 (empat) orang aparatur untuk menjalankan program PINDU. Jumlah sumberdaya aparatur yang menangani program PINDU ini tidak sebanding dengan Jumlah penduduk Kabupaten Pinrang pada Tahun 2017 yang berjumlah 369.595 jiwa. Akibatnya, banyak pelayanan informasi dan pengaduan yang tidak dapat ditangani dengan baik.

Pengaduan masyarakat masih banyak yang belum bisa diselesaikan oleh Pemerintah Kabupaten Pinrang. Adanya keterbatasan sumberdaya aparatur yang bertugas memberikan pelayanan pada Kantor PINDU me- nyebabkan pengaduan masyarakat tidak bisa cepat diselesaikan sehingga pelaksanaan PINDU berjalan kurang efektif. Selain sumberdaya aparatur, sarana dan prasarana menjadi aspek penunjang dalam mewujudkan penyelenggaraan pelayanan yang baik dan efektif. Dari hasil penelitian di lapangan, sarana dan prasarana yang ada pada Kantor PINDU Kabupaten Pinrang ternyata belum memadai dan masih terbatas. Sedangkan aspek informasi dan kewenangan sudah berjalan baik dengan dikeluarkannya Peraturan Bupati Pinrang Nomor 25 Tahun 2014 tentang Pembentukan PINDU Pemerintah Kabupaten Pinrang.

\section{Diposisi}

Pengangkatan birokrasi pada program PINDU di Kabupaten Pinrang sudah sesuai dengan aturan yang berlaku dengan adanya Keputusan Bupati Pinrang yang mengangkat dan menetapkan petugas pengelola PINDU. Namun, Pemerintah Kabupaten Pinrang dalam mengangkat petugas atau tenaga pengelola PINDU perlu memperhatikan syarat kemampuan dan pengetahuan aparatur tersebut, baik pemahamannya maupun latar belakang pendidikannya yang sesuai dengan bidang tugasnya agar sasaran dan tujuan pembentukan program PINDU dapat terwujud. Dari aspek insentif, petugas pengelola PINDU di Kabupaten Pinrang diberikan insentif sesuai dengan peraturan perundang-undangan yang berlaku. Petugas pengelola PINDU di Kabupaten Pinrang adalah Aparatur Sipil Negara yang diangkat sebagai pengelola PINDU melalui Keputusan Bupati, sedangkan anggaran penyelenggaraan program PINDU berasal dari APBD Kabupaten Pinrang, sehingga jumlah insentif yang diberikan kepada petugas pengelola PINDU mengacu pada peraturan perundang-undangan yang berlaku.

\section{Struktur Birokrasi}

Menurut Edwards III terdapat dua karakteristik utama dari birokrasi yakni: Standard Operational Procedure (SOP) dan fragmentasi.Dari hasil penelitian, implementasi pembentukan program PINDU di Kabupaten Pinrang telah dilengkapi dengan Standard operational procedure (SOP) pelayanan dan 
pengaduan. Aspek fragmentasi dalam implementasi pembentukan program PINDU di Kabupaten Pinrang melibatkan seluruh SKPD yang ada di Kabupaten Pinrang dengan pusat pengendali berada di Sub Bagian Tata Laksana dan Anjab pada Bagian Organisasi dan Tatalaksana Sekretariat Daerah Kabupaten Pinrang.

\section{Faktor Pendukung dan Penghambat Implementasi PINDU \\ Faktor Pendukung}

Support (political will)

Implementasi pembentukan program PINDU di Kabupaten Pinrang merupakan sebuah inovasi di bidang pelayanan informasi dan pengaduan, yang lahir dari kemauan politik Bupati Pinrang yang mengharapkan terwujudnya tata pemerintahan yang baik dan berintegritas dengan peningkatan partisipasi masyarakat dalam pelaksanaan dan pengawasan penyelenggaraan pemerintahan, pembangunan, dan pelayanan publik yang dilakukan oleh Pemerintah Kabupaten Pinrang bersama perangkat daerahnya.

Sumberdaya (capacity)

Dalam rangka implementasi pembentukan program PINDU, Pemerintah Kabupaten Pinrang telah menyiapkan dukungan sumberdaya (capacity) agar program PINDU dapat berjalan sesuai sasaran dan tujuan yang diharapkan. Dari sisi sumberdaya aparatur, program PINDU telah didukung oleh Tim Teknis PINDU yang diangkat dari aparatur sipil negara melalui Keputusan Bupati.

Nilai manfaat (value)

Implementasi pembentukan program PINDU di Kabupaten Pinrang memiliki nilai manfaat (value), baik manfaat bagi masyarakat maupun bagi Pemerintah Kabupaten Pinrang. Tujuan dari pembentukan program PINDU Kabupaten Pinrang adalah untuk menghadirkan pemerintahan yang baik dan berintegritas (good governance) di Kabupaten Pinrang.

\section{Faktor Penghambat}

Penentuan kanal akses

Petugas pelayanan PINDU di Kabupaten Pinrang yang berjumlah 4 (empat) orang, dalam pelaksanaan tugas masih sering melakukan kesalahan dalam penentuan kanal akses pelayanan informasi dan pengaduan. Kesalahan tersebut lebih disebabkan oleh kurangnya pengetahuan petugas layanan PINDU terkait tugas dan fungsi masing-masing SKPD/Unit Kerja.

Keterlibatan Pihak Non Pemerintah

Keterlibatan organisasi non pemerintah dalam implementasi pembentukan program PINDU di Kabupaten Pinrang masih sangat minim. Organisasi non pemerintah belum banyak yang ikut melibatkan diri dalam implementasi pembentukan program PINDU di Kabupaten Pinrang.

Pembiayaan Manajemen Perubahan

Pembiayaan dalam implementasi pembentukan program PINDU di Kabupaten Pinrang telah dianggarkan dalam APBD Kabupaten Pinrang setiap tahunnya. Anggaran yang dialokasikan dalam rangka implementasi program PINDU di Kabupaten Pinrang setiap tahun mengalami penurunan.

\section{Upaya Mengatasi Faktor Penghambat Implementasi Pembentukan Pindu Suasana Politik (Political Environment)}

Suasana politik (political environment) diantara unsur penyelenggara pemerintahan daerah Kabupaten Pinrang telah terbangun dengan baik dan berjalan kondusif. Pemerintah Kabupaten Pinrang selaku implementor program PINDU selalu melakukan komunikasi dengan pihak DPRD Kabupaten Pinrang dalam implementasi pembentukan PINDU di Kabupaten Pinrang.

\section{Kepemimpinan (Leadership)}

Upaya yang dilakukan untuk mengatasi berbagai hambatan yang muncul dalam implementasi pembentukan PINDU di Kabupaten Pinrang, dilakukan melalui praktek kepemimpinan (leadership) yang baik, memiliki komitmen dan bertanggung jawab terhadap program PINDU yang dijalankan.

\section{Perencanaan (Planning)}

Secara umum, implementasi pembentukan PINDU di Kabupaten Pinrang dilakukan melalui perencanaan (planning) yang baik dan terukur. Hambatan-hambatan yang muncul 
dalam proses implementasi telah mampu diatasi melalui kegiatan pengendalian dan evaluasi yang dilakukan setiap minggunya. Artinya, implementasi pembentukan PINDU di Kabupaten Pinrang, telah memiliki sistem perencanaan (planning) yang baik dari awal sampai akhir sehingga hambatan-hambatan yang muncul dalam implementasi pembentukan PINDU Kabupaten Pinrang dapat diatasi dan diminimalisir dengan baik.

\section{Pemerintah, Swasta, Masyarakat (Stake- holders)}

Pemerintah Kabupaten Pinrang telah menjalin sinergitas dengan semua pemangku kepentingan (stakeholders) yaitu private sector (swasta/dunia usaha) dan public sector (masyarakat) untuk mengatasi hambatanhambatan yang muncul dalam Implementasi pembentukan PINDU. Walaupun sinergitas yang terbangun antara Pemerintah Kabupaten Pinrang dengan pihak swasta dan masyarakat dalam penyelenggaraan PINDU sudah berjalan, namun hasinya belum optimal. Private sector (swasta/dunia usaha) yang berpartisipasi dalam pelaksanaan PINDU masih minim.

Transparansi Data (Transparency/visibility)

Implementasi pembentukan PINDU di Kabupaten Pinrang dilakukan secara transparan, sehingga mampu mengatasi hambatanhambatan dan permasalahan yang ada serta memberi kepercayaan masyarakat terhadap program PINDU di Kabupaten Pinrang.

\section{Finansial/Penganggaran (Budgets)}

Secara umum, Pemerintah Kabupaten Pinrang telah melakukan antisipasi terhadap hambatan yang akan muncul dalam implementasi program PINDU dengan memberikan dan menetapkan alokasi anggaran program PINDU Kabupaten Pinrang. Alokasi anggaran tersebut diperuntukkan untuk membiayai penyiapan sarana dan parasara penunjang PINDU, penyiapan sumberdaya aparatur petugas PINDU, dan pembiayaan operasional penyelenggaraan PINDU secara keseluruhan.

Sarana dan Prasarana Teknologi (Technology)

Sarana dan prasarana teknologi yang digunakan dalam program PINDU di Kabupaten Pinrang diantaranya adalah 4 (empat) unit komputer, 1 (satu) unit telepon seluler sebagai call center, 1 (satu) unit Anjungan Informasi PINDU, dan jaringan internet/wifi. Keberadaan sarana dan prasarana teknologi disiapkan untuk menunjang implementasi program PINDU di Kabupaten Pinrang.

\section{Inovasi (Innovation)}

Dalam rangka merangsang dan memotivasi lahirnya inovasi-inovasi baru, Bupati Pinrang mengadakan lomba kretivitas penyelengaraan pelayanan publik bagi seluruh SKPD/Unit Kerja di Kabupaten Pinrang. Salah satu unsur penilaian dalam kegiatan tersebut adalah dengan melihat SKPD/Unit Kerja mana yang paling inovatif dan berhasil dalam memberikan pelayanan publik.

\section{SIMPULAN}

Implementasi pembentukan PINDU di Kabupaten Pinrang Provinsi Sulawesi Selatan, dapat disimpulkan sebagai berikut :

1. Implementasi pembentukan PINDU di Kabupaten Pinrang Provinsi Sulawesi Selatan, ditinjau dari dimensi komunikasi, sumberdaya, disposisi, dan struktur birokrasi, yaitu:

a. Dimensi Komunikasi

Secara umum, komunikasi yang dibangun oleh Pemerintah Kabupaten Pinrang, baik dari aspek transmisi (trasmission), kejelasan (clarity) dan konsistensi (consistency) kebijakan, sudah berjalan sesuai dengan tujuan dan sasaran kebijakan yang diharapkan.

b. Dimensi Sumberdaya

Secara umum, sumberdaya yang digunakan belum efektif, baik dari aspek sumberdaya aparatur maupun aspek sumberdaya sarana dan prasarana. Namun, pada aspek informasi dan kewenangan, sudah berjalan baik dengan dikeluarkannya Peraturan Bupati Pinrang Nomor 25 Tahun 2014 tentang Pembentukan PINDU Pemerintah Kabupaten Pinrang.

c. Dimensi Disposisi

Secara umum, dimensi disposisi ditinjau dari aspek pengangkatan birokrasi pada prinsipnya sudah berjalan sesuai dengan 
peraturan yang berlaku, namun belum efektif karena tidak memperhatikan syarat kemampuan dan pengetahuan serta latar belakang pendidikan apartur yang bersangkutan. Sedangkan dari aspek insentif, pada prinsipnya sudah berjalan sesuai dengan peraturan perundangundangan yang berlaku.

d. Dimensi Struktur Birokrasi

Secara umum, pada dimensi struktur birokrasi, ditinjau dari aspek Standar Operasional Prosedur (SOP) PINDU maupun aspek fragmentasi pertanggungjawaban, program PINDU di Kabupaten Pinrang sudah dijalankan sesuai Standar Operasional Prosedur (SOP) PINDU dengan fragmentasi pertanggungjawaban yang juga baik.

Dari empat dimensi di atas, dimensi yang belum efektif adalah dimensi sumberdaya aparatur pada kantor PINDU, baik dari sisi kuantitas maupun kualitas karena jumlah sumberdaya aparatur yang menangani program PINDU ini tidak sebanding dengan jumlah penduduk Kabupaten Pinrang pada Tahun 2017 yang berjumlah 369.595 jiwa. Akibatnya, banyak pelayanan informasi dan pengaduan yang tidak dapat ditangani dengan baik.

2. Faktor pendukung dan faktor penghambat implementasi pembentukan PINDU disimpulkan sebagai berikut :

a. Faktor pendukung

Implementasi pembentukan PINDU didukung oleh faktor-faktor sebagai berikut :

1) Faktor support (political will), dimana pembentukan program PINDU lahir dari adanya kemauan politik (political will) dan dukungan dari para pengambil kebijakan di Kabupaten Pinrang;

2) Faktor sumberdaya (capacity), dimana pembentukan program PINDU didukung dengan ketersediaan sumberdaya (capacity), baik sumberdaya aparatur, informasi yang cukup, ke- wenangan, dan sarana parasarana serta anggaran yang cukup; dan

3) Faktor nilai manfaat (value), dimana pembentukan program PINDU memiliki nilai manfaat yang sangat baik dalam meningkatkan partisipasi masyarakat dan meningkatkan kinerja pelayanan aparatur sehingga pada akhirnya dapat mewujudkan tata kelola pemerintahan yang baik dan berintegritas.

b. Faktor penghambat

Faktor-faktor yang menghambat implementasi pembentukan PINDU, yaitu :

1) Adanya kesalahan-kesalahan dan kekeliruan dalam penentuan kanal akses pada program PINDU sehingga penyelesaian masalah oleh SKPD/ Unit Kerja terhadap pengaduan masyarakat menjadi tidak tepat sasaran;

2) Minimnya keterlibatan pihak non pemerintah dalam program PINDU; dan

3) Adanya penurunan alokasi anggaran PINDU setiap tahunnya sehingga menghambat operasionalisasi pelayanan PINDU.

3. Upaya yang dilakukan untuk mengatasi faktor penghambat implementasi pembentukan PINDU, yaitu :

a. Membangun suasana politik (political environment) yang kondusif dengan para perumus kebijakan;

b. Menjalankan kepemimpinan (leadership) yang baik;

c. Melakukan perencanaan (planning) yang komprehensif;

d. Membangun sinergitas dengan semua stakeholders;

e. Menjalankan transparansi data (transparency/visibility) dalam pelayanan;

f. Memberikan alokasi anggaran (budgets) yang memadai;

g. Menyediakan sarana prasarana teknologi (technology) pendukung;

h. Merangsang serta memotivasi lahirnya inovasi (Innovation) dan kreativitas baru pada setiap SKPD/Unit Kerja dalam penyelenggaraan pelayanan publik. 


\section{DAFTAR RUJUKAN}

Indrajit, Eko. 2006. Electronic Government. Yogyakarta: Andi

Manullang. 2009. Dasar-Dasar Manajemen. Jakarta: Ghalia Indonesia

Moleong, Lexy J. 2013. Metode Penelitian Kualitatif. Bandung: Remaja Rosdakarya

Silalahi, Uber. 2012. Metode Penelitian Sosial. Bandung: Reflika
Simangunsong, Fernandes. 2016. Metode Penelitian Pemerintahan. Bandung: Alfabeta

Waluyo. 2007. Manajemen Publik: Konsep, Aplikasi dan Implementasinya Dalam Pelaksanaan Otonomi Daerah. Jakarta: Bumi Aksara

Widodo, Joko. 2010. Analisis Kebijakan Publik. Malang: Bayumedia 